\section{Aborto e coerção sexual: o contexto de vulnerabilidade entre mulheres jovens}

\author{
Sexual coercion and abortion: a context of \\ vulnerability among youth women
}

\section{Abstract}

This study aims to investigate the relationship between abortion and experiences of sexual coercion. The data came from GRAVAD, a household survey with a stratified random sample of young women (18-24 years) in Rio de Janeiro, Porto Alegre, and Salvador, Brazil. The sample used in this article included 870 interviews of women who reported having become pregnant. Abortion was associated with: a reported experience of sexual coercion, more schooling, failure to obtain first information about sex from parents, and a history of more pregnancies and sexual partners. The association between abortion and sexual coercion reflects a situation of gender vulnerability and reveals young women's precariousness in sex negotiation and reproduction. A veil of silence in public agencies concerning sexual coercion helps perpetuate young women's vulnerability, as it blocks access to the appropriate educational, legal, and health services.

Induced Abortion; Sexual Violence; Vulnerability
Flávia Bulegon Pilecco 1 Daniela Riva Knauth 1 Álvaro Vigo 1

\section{Introdução}

No Brasil, o aborto destaca-se como um grave problema de saúde pública à medida que é amplamente praticado, muitas vezes de forma insegura, dentro de um cenário de clandestinidade 1 . A ilegalidade do aborto não coíbe a prática e perpetua as iniquidades socioeconômicas em que é realizado. Há, assim, um contexto que impõe às mulheres oportunidades desiguais de evitar uma gravidez ou de escolher seu desfecho ${ }^{2}$. São especialmente as mulheres mais pobres aquelas que se submetem aos riscos da prática de um aborto realizado em condições precárias ${ }^{3}$.

O aborto na adolescência representa $7 \%$ a $9 \%$ do total de abortos provocados no Brasil, e 72,5\% a $78 \%$ deles ocorrem em jovens na faixa etária de 17 a 19 anos, que estão em um relacionamento estável e que são dependentes economicamente da família ou do parceiro. Nesses casos, o aborto geralmente resulta de gravidez não prevista e é feito por meio do uso de misoprostol ${ }^{3}$. Dados provenientes de uma compilação de estudos internacionais indicam que mulheres de 20 a 24 anos são as que possuem o maior número absoluto de abortos, enquanto as com menos de 20 anos e as com mais de 40 anos são as que têm os menores. Apesar disso, as mulheres nos extremos reprodutivos apresentam maior proporção de gravidezes findadas em aborto. Enquanto as mulheres mais jovens alegam ser muito novas 
para ter filhos, as de mais idade alegam já ter a quantidade de filhos que planejaram ${ }^{4}$.

Determinantes como a origem social, as configurações familiares e de conjugalidade, as redes de sociabilidade, os projetos de maternidade, o percurso escolar e a inserção no mercado de trabalho, influenciam na decisão das jovens quanto à manutenção ou à interrupção da gravidez. Em estudos anteriores desenvolvidos com os dados da pesquisa GRAVAD (Gravidez na Adolescência: Estudo Multicêntrico sobre Jovens, Sexualidade e Reprodução no Brasil) 1, inquérito sobre sexualidade e saúde reprodutiva desenvolvido em três capitais brasileiras 5, encontrou-se associação positiva entre alta escolaridade e renda familiar mais elevada e a ocorrência de aborto na primeira gravidez. Dessa forma, as jovens mais privilegiadas economicamente, além de ter maior acesso à contracepção, podem optar por um aborto mais seguro, ainda que de forma ilegal. As jovens que tiveram seu primeiro filho após os 19 anos (em contraste com as que tiveram na adolescência), as que se iniciaram sexualmente com parceiro eventual, as que ainda estavam estudando e aquelas que faziam uso de contracepção na época da gravidez, relataram maior ocorrência de aborto 5,6.

A ilegalidade do aborto faz que sua real magnitude seja desconhecida e suas consequências para a saúde das mulheres obscurecidas.

Tanto quanto o aborto, a coerção sexual é outra questão silenciada. Por definição, coerção sexual é "o ato de forçar (ou a tentativa de forçar) um indivíduo, por meio de violência, ameaças, insistência verbal, engano, expectativas culturais ou circunstâncias econômicas, a ter um determinado comportamento sexual contra a sua vontade" 7 (p. 6). Essa categoria tem sido utilizada em estudos recentes sobre violência com o intuito de contemplar as mais diversas formas de repressão do exercício da sexualidade e de obtenção de sexo forçado ${ }^{8}$. A coerção sexual não pressupõe necessariamente o ato sexual, mas contempla um conjunto maior de atos de violência física e simbólica que constrange ou obriga a práticas sexuais contra a vontade. Ela é entendida não como um evento isolado, mas como um processo que se traduz na restrição da liberdade sexual individual, mediante constrangimentos como pressão verbal, social, chantagens e uso de violência física 8 .

A multiplicidade de interpretações do que é considerado violência sexual e, em especial, coerção, dificulta a comparabilidade dos estudos desenvolvidos nessa temática ${ }^{9}$. Cordeiro et al. ${ }^{8}$, estudando dados do inquérito GRAVAD, destacam a importância de se trabalhar a coerção aliada à noção de negociação sexual, na qual as formas de expressar o desejo e a interação são influenciadas pelo contexto sociocultural no qual os pares estão inseridos e pelas relações de gênero envolvidas. Nesse contexto, a assimetria de gênero pode repercutir em maior vulnerabilidade das mulheres em relação aos homens na esfera sexual 10.

A associação entre esses dois eventos, coerção sexual e aborto provocado, deve ser analisada dentro do marco teórico da vulnerabilidade. Tal conceito busca romper com a visão clássica de risco, centrada no indivíduo, propondo que, para além dos aspectos individuais, há um conjunto de outros determinantes que condicionam os comportamentos individuais e a maior ou menor exposição ao risco ${ }^{11}$. É nesse sentido que o quadro teórico da vulnerabilidade destaca três planos interdependentes que devem ser considerados na análise da vulnerabilidade: o plano individual, no qual a vulnerabilidade é relacionada a comportamentos que implicam exposição e suscetibilidade do indivíduo e que podem variar ao longo do tempo em função de valores e recursos que permitam maior ou menor proteção; o plano social, no qual é avaliada a coletividade, por intermédio do acesso à informação e aos serviços de saúde, dos indicadores epidemiológicos, de aspectos sociopolíticos, culturais e econômicos e do grau de liberdade de pensamento e expressão; e o plano programático, no qual a vulnerabilidade se relaciona à proposição, ao cumprimento e à continuidade de políticas, programas, serviços ou ações voltadas à resolução do problema ${ }^{12}$.

Dentro dessa perspectiva, o presente artigo se propõe a analisar a relação entre aborto e coerção sexual. Nosso objetivo é evidenciar os determinantes individuais, sociais e programáticos, vinculados à prática do aborto entre mulheres jovens.

\section{Metodologia}

Os dados analisados são provenientes do estudo GRAVAD, uma pesquisa multicêntrica, de base populacional, realizada de outubro de 2001 a janeiro de 2002, no Rio de Janeiro, em Porto Alegre e em Salvador e que incluiu jovens de 18 a 24 anos completos, de ambos os sexos. A opção pelas três cidades foi realizada com o intuito de apreender contextos socioculturais e econômicos bastante distintos. A escolha em estudar jovens de uma faixa etária que não condissesse com a classificada como adolescência (de 10 a 19 anos) pela Organização Mundial da Saúde foi feita com vistas à avaliação, por parte dos entrevistados, dos desfechos resultantes de uma gravidez em tal fase da vida, em um período próximo a tal evento 
reprodutivo, além de evitar questões éticas envolvidas ao se entrevistar menores de idade. $\mathrm{O}$ estudo foi elaborado com delineamento transversal e amostragem probabilística estratificada em três estágios. Em um primeiro estágio, em cada cidade, os setores censitários foram estratificados segundo a escolaridade e a renda média do chefe do domicílio e, em cada estrato, foram escolhidos aleatoriamente 55 setores, de modo proporcional ao número de jovens entre 18 a 24 anos existentes em cada um deles. No segundo estágio, realizou-se um levantamento de todos os domicílios particulares permanentes nos setores selecionados para identificação dos jovens na faixa etária de interesse, sendo sorteadas 33 unidades domiciliares para compor a amostra. No terceiro e último estágio, em cada domicílio sorteado, foi selecionado um jovem entre os elegíveis. Em caso de mais de um jovem elegível, para evitar o efeito de conglomerado, adotou-se o critério de desempate de selecionar aquela/e cujo dia e mês de aniversário fosse o primeiro do ano civil, independente do ano de nascimento. A amostra inicial estimada era de 4.500 jovens e a final totalizou 4.634 jovens entrevistados, sendo 1.442 jovens de Porto Alegre, 1.528 do Rio de Janeiro e 1.664 de Salvador.

$\mathrm{O}$ instrumento quantitativo foi estruturado de acordo com as informações obtidas na etapa qualitativa precedente, que contou com entrevistas em profundidade de 123 jovens, residentes nas cidades estudadas e estando na faixa etária de interesse. A coleta de dados foi feita mediante entrevista face a face, conduzida por pesquisadores treinados, em sua maioria provenientes de cursos de graduação de ciências sociais ou de saúde coletiva e na mesma faixa etária dos pesquisados, para melhorar a qualidade das respostas coletadas. A manifestação, por parte dos entrevistados, de incômodo resultante da entrevista feita por entrevistador de outro sexo, possibilitava a troca do entrevistador. Esses procedimentos resultaram em um alto índice de respondentes $(85,2 \%)$ e possibilitaram que questões de caráter bastante sensível, como aquelas que dizem respeito ao aborto e às experiências de coerção sexual, fossem abordadas com maior pertinência cultural e, portanto, com mais chances de obtenção de dados fidedignos.

$\mathrm{Na}$ análise do presente artigo, foram utilizados os dados referentes a 870 jovens do sexo feminino que relataram ter tido ao menos uma gravidez. Foram excluídos todos os homens e as mulheres que declararam não ter tido gravidez ou que não prestaram essa informação. A coerção sexual foi avaliada na pesquisa GRAVAD pela pergunta "Alguém tentou forçar você a ter relações sexuais contra a sua vontade?”, cujas opções de resposta eram: "Sim, uma vez", "Sim, várias vezes”, “Não” e "Recusou-se a responder". Para fins de análise, as primeiras duas respostas foram reunidas na categoria "Sim".

Inicialmente, foi realizada uma análise descritiva da amostra com e sem estrutura do delineamento e pesos amostrais. A amostra foi ponderada de acordo com a probabilidade de seleção das unidades amostrais em cada estágio. As tabelas descritivas (Tabelas 1 e 2) apresentam essas duas análises da amostra, com o intuito de fornecer ao leitor o número efetivo de sujeitos respondentes (nas duas primeiras colunas de ambas as tabelas), além de mostrar a importância da inclusão do delineamento e dos pesos amostrais (nas duas últimas colunas) para que os resultados pudessem ser generalizados à população de referência.

Na sequência, o modelo de regressão de Poisson com variância robusta univariável foi utilizado para descrever a associação entre o desfecho, aborto provocado, e os preditores (Tabela 3). Nesse modelo também foram incorporadas a estrutura do delineamento amostral e a ponderação para garantir a representatividade dos centros. O teste da razão de verossimilhança foi usado para selecionar as variáveis para o modelo multivariável $(\mathrm{p}<0,2)$, sendo mantidas aquelas significativas a $5 \%$. Todas as análises foram realizadas pela utilização do programa Stata, versão 9.0 (Stata Corp., College Station, Estados Unidos), pela capacidade do programa de incorporar efeitos do delineamento e pesos amostrais dentro do comando survey (svy).

As variáveis que compuseram o modelo foram: idade da jovem no momento da entrevista, cor autorreferida, escolaridade, cidade onde a jovem residia, religião de criação, responsabilidade sobre o trabalho doméstico entre 15 e 18 anos, se exercia alguma atividade remunerada no momento da entrevista, situação socioeconômica (por meio do proxi escolaridade da mãe), se obteve as primeiras informações sobre sexo com os pais, idade de iniciação sexual, quem era o(a) parceiro(a) dessa primeira relação, tempo transcorrido desde a iniciação sexual, padrão de uso de métodos contraceptivos (avaliado em duas ocasiões da vida sexual da jovem - iniciação sexual e última relação - e do tipo de método usado nessas ocasiões, visando à proteção - condom nas duas ocasiões -, contracepção - uso de outro método que não o condom em uma das duas ocasiões - e a não preocupação com proteção ou contracepção - denotada pelo não uso de método em uma das duas ocasiões) 13, número de parceiros(as) sexuais, idade na primeira gravidez, diferença de idade para o parceiro da primeira gestação, número de gestações e o relato 
Descrição da amostra de mulheres de acordo com autorrelato de aborto provocado.

\begin{tabular}{|c|c|c|c|c|}
\hline \multirow[t]{3}{*}{ Características } & \multicolumn{2}{|c|}{ Sem plano complexo * } & \multicolumn{2}{|c|}{ Com plano complexo ** } \\
\hline & Sem aborto & Com aborto & Sem aborto & Com aborto \\
\hline & n (\%) & n (\%) & $\%$ & $\%$ \\
\hline \multicolumn{5}{|l|}{ Relato de ter sofrido coerção sexual } \\
\hline Não & $568(81,4)$ & $109(63,4)$ & 80,6 & 64,8 \\
\hline Sim, uma vez & $82(11,7)$ & $43(25,0)$ & 13,1 & 26,8 \\
\hline Sim, várias vezes & $48(6,9)$ & $20(11,6)$ & 6,3 & 8,4 \\
\hline \multicolumn{5}{|l|}{ Escolaridade da mãe } \\
\hline Nunca frequentou/Ensino Fundamental & $491(76,7)$ & $99(62,7)$ & 77,1 & 64,5 \\
\hline Ensino Médio/Ensino Superior & $149(23,3)$ & $59(37,3)$ & 22,9 & 35,5 \\
\hline \multicolumn{5}{|l|}{ Cidade } \\
\hline Rio de Janeiro & $214(30,7)$ & $61(35,5)$ & 51,7 & 52,8 \\
\hline Porto Alegre & $214(30,7)$ & $22(12,8)$ & 14,3 & 5,1 \\
\hline Salvador & $270(38,6)$ & $89(51,7)$ & 34,0 & 42,1 \\
\hline \multicolumn{5}{|l|}{ Parceiro da primeira relação sexual } \\
\hline Namorado/Marido/Companheiro & $639(91,6)$ & $143(83,6)$ & 92,8 & 84,7 \\
\hline Pessoa com quem você "ficou"/Outro & $59(8,4)$ & $28(16,4)$ & 7,2 & 15,3 \\
\hline \multirow{2}{*}{\multicolumn{5}{|c|}{$\begin{array}{l}\text { Obteve as primeiras informações sobre relações } \\
\text { sexuais com seu pai ou sua mãe }\end{array}$}} \\
\hline & & & & \\
\hline Sim & $218(31,6)$ & $41(23,0)$ & 37,9 & 20,9 \\
\hline Não & $473(68,4)$ & $130(76,0)$ & 62,1 & 79,1 \\
\hline \multicolumn{5}{|l|}{ Idade na iniciação sexual } \\
\hline Iniciação precoce (até 15 anos) & $295(42,4)$ & $95(55,2)$ & 41,6 & 53,0 \\
\hline Iniciação média (de 15 até 18 anos) & $244(35,1)$ & $52(30,2)$ & 34,1 & 30,4 \\
\hline Iniciação tardia (mais de 18 anos) & $157(22,6)$ & $25(14,5)$ & 24,3 & 16,6 \\
\hline \multicolumn{5}{|l|}{ Número de parceiros sexuais } \\
\hline 1 & $270(39,5)$ & $23(13,8)$ & 36,8 & 14,3 \\
\hline $2-4$ & $329(48,2)$ & $80(47,9)$ & 50,0 & 49,3 \\
\hline 5 ou mais & $84(12,3)$ & $64(38,3)$ & 13,2 & 36,4 \\
\hline \multicolumn{5}{|l|}{ Métodos usados na primeira e na última relação } \\
\hline Proteção & $353(52,8)$ & $67(39,6)$ & 50,6 & 39,6 \\
\hline Contracepção & $40(6,0)$ & $11(6,5)$ & 9,5 & 6,3 \\
\hline Não usaram método nenhum & $275(41,2)$ & $91(53,9)$ & 39,9 & 54,1 \\
\hline \multicolumn{5}{|l|}{ Escolaridade da jovem } \\
\hline Ensino Fundamental incompleto & $282(41,1)$ & $56(33,7)$ & 38,3 & 29,7 \\
\hline Ensino Fundamental completo & $226(32,9)$ & $37(22,3)$ & 36,5 & 22,7 \\
\hline Ensino Médio & $153(22,2)$ & $44(26,5)$ & 23,1 & 34,8 \\
\hline Ensino Superior/Pós-graduação & $26(3,8)$ & $29(17,5)$ & 2,1 & 12,8 \\
\hline \multicolumn{5}{|l|}{ Exerce alguma atividade com rendimentos } \\
\hline Sim & $255(36,5)$ & $79(45,9)$ & 38,9 & 51,8 \\
\hline \multirow[t]{2}{*}{ Não } & $443(63,5)$ & $93(54,1)$ & 61,1 & 48,2 \\
\hline & Média (EP) & Média (EP) & Média (EP) & Média (EP) \\
\hline Idade da jovem & $21,4(0,07)$ & $21,7(0,15)$ & $21,3(0,10)$ & $21,7(0,18)$ \\
\hline Tempo desde a iniciação sexual & $5,4(0,09)$ & $6,3(0,17)$ & $5,1(0,11)$ & $6,0(0,20)$ \\
\hline Número de gestações & $1,5(0,03)$ & $1,93(0,08)$ & $1,5(0,05)$ & $1,89(0,10)$ \\
\hline
\end{tabular}

EP: erro-padrão da média.

* Analisado como uma amostra aleatória simples;

** Analisado com expansão da amostra e estrutura do delineamento.

Fonte: Pesquisa GRAVAD, 2002. 


\section{Tabela 2}

Descrição das características sociodemográficas associadas ao autorrelato de coerção sexual segundo a declaração de aborto.

\begin{tabular}{|c|c|c|c|c|}
\hline \multirow[t]{3}{*}{ Características } & \multicolumn{2}{|c|}{ Sem plano complexo * } & \multicolumn{2}{|c|}{ Com plano complexo ** } \\
\hline & Sem aborto & Com aborto & Sem aborto & Com aborto \\
\hline & n (\%) & n (\%) & $\%$ & $\%$ \\
\hline \multicolumn{5}{|l|}{ Escolaridade da mãe } \\
\hline Nunca frequentou/Ensino Fundamental & $89(76,7)$ & $38(69,1)$ & 78,2 & 70,8 \\
\hline Ensino Médio/Ensino Superior & $27(23,3)$ & $17(30,9)$ & 21,8 & 29,2 \\
\hline \multicolumn{5}{|l|}{ Idade que tinha no primeiro episódio de coerção (anos) } \\
\hline Até 10 & $10(8,0)$ & $3(5,1)$ & 8,1 & 3,6 \\
\hline $10-19$ & $101(81,5)$ & $43(72,9)$ & 85,7 & 77,5 \\
\hline $20-24$ & $13(10,5)$ & $13(22,0)$ & 6,2 & 18,9 \\
\hline \multicolumn{5}{|l|}{ Autor da coerção } \\
\hline Sempre a mesma pessoa & $33(68,8)$ & $13(65,0)$ & 62,9 & 67,3 \\
\hline Nem sempre a mesma pessoa & $15(31,2)$ & $7(35,0)$ & 37,1 & 32,7 \\
\hline \multicolumn{5}{|l|}{ O que aconteceu? } \\
\hline A relação sexual realmente aconteceu & $34(26,4)$ & $16(25,4)$ & 22,2 & 29,1 \\
\hline Ficou só na tentativa & $95(73,6)$ & $47(74,6)$ & 77,8 & 70,9 \\
\hline \multicolumn{5}{|l|}{ Forma de coerção } \\
\hline Violência física & $23(17,7)$ & $13(20,6)$ & 18,4 & 25,5 \\
\hline Ameaça de violência & $20(15,4)$ & $7(11,1)$ & 13,3 & 17,8 \\
\hline Outro tipo de ameaça & $6(4,6)$ & $4(6,4)$ & 3,8 & 5,0 \\
\hline Houve muita insistência & $78(60,0)$ & $38(60,3)$ & 62,7 & 51,0 \\
\hline Outro & $3(2,3)$ & $1(1,6)$ & 1,8 & 0,7 \\
\hline \multicolumn{5}{|l|}{ Relação do perpetrador com a jovem } \\
\hline Pai/Mãe/Irmão(ã)/Outro parente & $13(10,1)$ & $4(6,7)$ & 5,2 & 5,3 \\
\hline Padrasto/Madrasta & $4(3,1)$ & $3(5,0)$ & 1,5 & 1,5 \\
\hline Amigo(a)/Vizinho(a) & $29(22,5)$ & $10(16,7)$ & 27,7 & 16,7 \\
\hline Parceiro(a) ou ex-parceiro(a) de relacionamento & $54(41,9)$ & $24(40,0)$ & 39,5 & 37,0 \\
\hline Pessoa desconhecida & $3(2,3)$ & $6(10,0)$ & 1,2 & 13,9 \\
\hline Chefe/Patrão(oa) & $3(2,3)$ & $1(16,7)$ & 2,6 & 0,4 \\
\hline Outro & $23(17,8)$ & $12(20,0)$ & 22,3 & 25,2 \\
\hline \multicolumn{5}{|l|}{ Idade do agressor (anos) } \\
\hline Até 19 & $28(22,8)$ & $15(26,3)$ & 29,0 & 23,2 \\
\hline $20-29$ & $74(60,2)$ & $32(56,1)$ & 51,9 & 58,0 \\
\hline $30-39$ & $15(12,2)$ & $7(12,3)$ & 11,5 & 14,8 \\
\hline $40-49$ & $3(2,4)$ & $1(1,8)$ & 6,0 & 1,0 \\
\hline 50 ou mais & $3(2,4)$ & $2(3,5)$ & 1,6 & 3,0 \\
\hline \multicolumn{5}{|l|}{ Revelação da coerção } \\
\hline Sim & $72(56,2)$ & $43(70,5)$ & 58,1 & 73,1 \\
\hline Não & $56(43,8)$ & $18(29,5)$ & 41,9 & 26,9 \\
\hline \multicolumn{5}{|l|}{ Pessoa para quem revelou o episódio de coerção } \\
\hline Pai & $8(11,8)$ & $5(10,6)$ & 3,6 & 17,0 \\
\hline Mãe & $20(29,4)$ & $11(23,4)$ & 16,3 & 20,7 \\
\hline Amigos(as)/Colegas & $29(42,6)$ & $22(46,8)$ & 48,1 & 56,2 \\
\hline Polícia & $2(2,9)$ & $2(4,3)$ & 1,0 & 7,0 \\
\hline Professores & $2(2,9)$ & $1(2,1)$ & 1,9 & 2,3 \\
\hline Médicos & $3(4,4)$ & $0(0,0)$ & 1,0 & 0,0 \\
\hline Parceiro(a) & $4(5,9)$ & $6(12,8)$ & 10,8 & 9,2 \\
\hline
\end{tabular}

* Analisado como uma amostra aleatória simples;

** Analisado com expansão da amostra e estrutura do delineamento.

Fonte: Pesquisa GRAVAD, 2002. 
Associações uni e multivariáveis entre características das jovens e a declaração de aborto provocado.

\begin{tabular}{|c|c|c|c|c|}
\hline & \multicolumn{2}{|c|}{ Análise univariável } & \multicolumn{2}{|c|}{ Análise multivariável } \\
\hline & $\mathrm{RP}$ * & IC95\% & $\mathrm{RP} * *$ & IC95\% \\
\hline \multicolumn{5}{|l|}{ Relato de ter sofrido coerção sexual } \\
\hline Não & 1,00 & - & 1,00 & - \\
\hline Sim, uma vez & 1,99 & $1,29-3,06$ & 1,60 & $1,04-2,44$ \\
\hline Sim, várias vezes & 1,49 & $0,89-2,49$ & 0,77 & $0,41-1,46$ \\
\hline \multicolumn{5}{|l|}{ Escolaridade da mãe } \\
\hline Nunca frequentou/Ensino Fundamental & 1,00 & - & - & - \\
\hline Ensino Médio/Ensino Superior & 1,60 & $1,10-2,32$ & - & - \\
\hline \multicolumn{5}{|l|}{ Cidade } \\
\hline Porto Alegre & 1,00 & - & 1,00 & - \\
\hline Rio de Janeiro & 2,46 & $1,33-4,53$ & 2,16 & $1,22-3,83$ \\
\hline Salvador & 2,86 & $1,63-4,99$ & 2,75 & $1,63-4,65$ \\
\hline \multicolumn{5}{|l|}{ Parceiro da primeira relação sexual } \\
\hline Namorado/Marido/Companheiro & 1,00 & - & - & - \\
\hline Pessoa com quem você "ficou"/Outro & 1,85 & $1,23-2,78$ & - & - \\
\hline \multicolumn{5}{|c|}{$\begin{array}{l}\text { Obteve as primeiras informações sobre relações sexuais com seu } \\
\text { pai ou sua mãe }\end{array}$} \\
\hline Sim & 1,00 & - & 1,00 & - \\
\hline Não & 1,97 & $1,17-3,29$ & 1,90 & $1,14-3,18$ \\
\hline \multicolumn{5}{|l|}{ Idade na iniciação sexual } \\
\hline Iniciação precoce (até 15 anos) & 1,00 & - & - & - \\
\hline Iniciação média (de 15 até 18 anos) & 1,64 & $1,05-2,56$ & - & - \\
\hline Iniciação tardia (mais de 18 anos) & 1,25 & $0,67-2,33$ & - & - \\
\hline \multicolumn{5}{|l|}{ Número de parceiros sexuais } \\
\hline 1 & 1,00 & - & 1,00 & - \\
\hline $2-4$ & 2,22 & $1,18-4,17$ & 2,21 & $1,31-3,75$ \\
\hline 5 ou mais & 4,50 & $2,39-8,46$ & 2,66 & $1,53-4,60$ \\
\hline \multicolumn{5}{|c|}{ Métodos usados na primeira e na última relação } \\
\hline Não usaram método nenhum & 1,00 & - & - & - \\
\hline Contracepção & 0,57 & $0,26-1,23$ & - & - \\
\hline Proteção & 0,65 & $0,47-0,90$ & - & - \\
\hline \multicolumn{5}{|l|}{ Escolaridade da jovem } \\
\hline Ensino Fundamental incompleto & 1,00 & - & 1,00 & - \\
\hline Ensino Fundamental completo & 0,83 & $0,50-1,39$ & 1,15 & $0,71-1,88$ \\
\hline Ensino Médio & 1,68 & $1,09-2,59$ & 2,78 & $1,77-4,36$ \\
\hline Ensino Superior/Pós-graduação & 3,62 & $2,08-6,30$ & 6,47 & $3,47-12,07$ \\
\hline \multicolumn{5}{|l|}{ Exerce alguma atividade com rendimentos } \\
\hline $\operatorname{Sim}$ & 1,00 & - & - & - \\
\hline Não & 1,50 & $1,07-2,12$ & - & - \\
\hline Idade da jovem & 1,10 & $1,01-1,20$ & - & - \\
\hline Tempo desde a iniciação sexual & 1,15 & $1,08-1,22$ & - & - \\
\hline Número de gestações & 1,33 & $1,16-1,52$ & 1,65 & $1,40-1,94$ \\
\hline
\end{tabular}

IC95\%: intervalo de 95\% de confiança; RP: razão de prevalência.

* Estimada pela regressão de Poisson robusta;

** Ajustada pelas demais variáveis do modelo.

Fonte: Pesquisa GRAVAD, 2002. 
de alguém ter tentado forçar a jovem a ter relações sexuais contra a vontade.

Com o objetivo de elucidar a relação entre aborto (que é mais frequente entre mulheres de classes socioeconômicas mais elevadas) e declaração de coerção sexual (cuja maior frequência ocorre nas classes socioeconômicas mais baixas), foi feita uma regressão de Poisson com variância robusta univariável, estratificada por classes socioeconômicas, apresentada na Figura 1.

Este estudo obteve aprovação dos comitês de ética dos três centros acadêmicos envolvidos (Universidade Federal do Rio Grande do Sul, Universidade do Estado do Rio de Janeiro e Universidade Federal da Bahia), possibilitando aos entrevistados a recusa ou a interrupção do questionário a qualquer momento e assegurado o anonimato e confidencialidade das respostas, com a assinatura do Termo de Consentimento Livre e Esclarecido, em consonância com a Resolução $n^{o}$. 196/96 do Conselho Nacional de Ética em Pesquisa.

\section{Resultados}

Dentre as mulheres estudadas, que relataram ao menos uma gravidez, $172(21,5 \%)$ relataram ao menos um episódio de aborto provocado. Já no que se refere à declaração de coerção sexu- al, do total de mulheres entrevistadas, 125 (16\%) informaram que a coerção ocorreu uma vez e $68(6,8 \%)$ declararam que ocorreu várias vezes (prevalências estimadas, incorporando desenho e pesos amostrais) (dados não apresentados).

A Tabela 1 descreve características relativas às mulheres que recorreram e às que não recorreram ao aborto. Somente foram apresentadas as variáveis que na análise univariável tiveram associação estatisticamente significativa com a declaração de aborto provocado. A declaração de coerção sexual foi superior entre as mulheres que relataram aborto quando em comparação às que não abortaram, sendo o dobro para as que declararam que a coerção ocorreu uma vez (26,8\% entre as que abortaram e $13,1 \%$ entre as que não abortaram). As mulheres que declararam ter abortado, em comparação às que não o fizeram, caracterizavam-se por pertencerem às classes sociais mais elevadas, utilizando-se como proxi a escolaridade da mãe (35,5\% para aquelas com mães com maior escolaridade versus $22,9 \%$ para as de menor escolaridade), ter maior escolaridade $(47,6 \%$ tinham ao menos o ensino médio completo, em comparação com $25,2 \%$ das que não relataram aborto), pelo relato menos frequente de obtenção das primeiras informações sobre relações sexuais com os pais $(20,9 \%$ versus $37,9 \%)$, pela maior inserção no mercado de trabalho no momento da entrevista $(51,8 \%$ versus

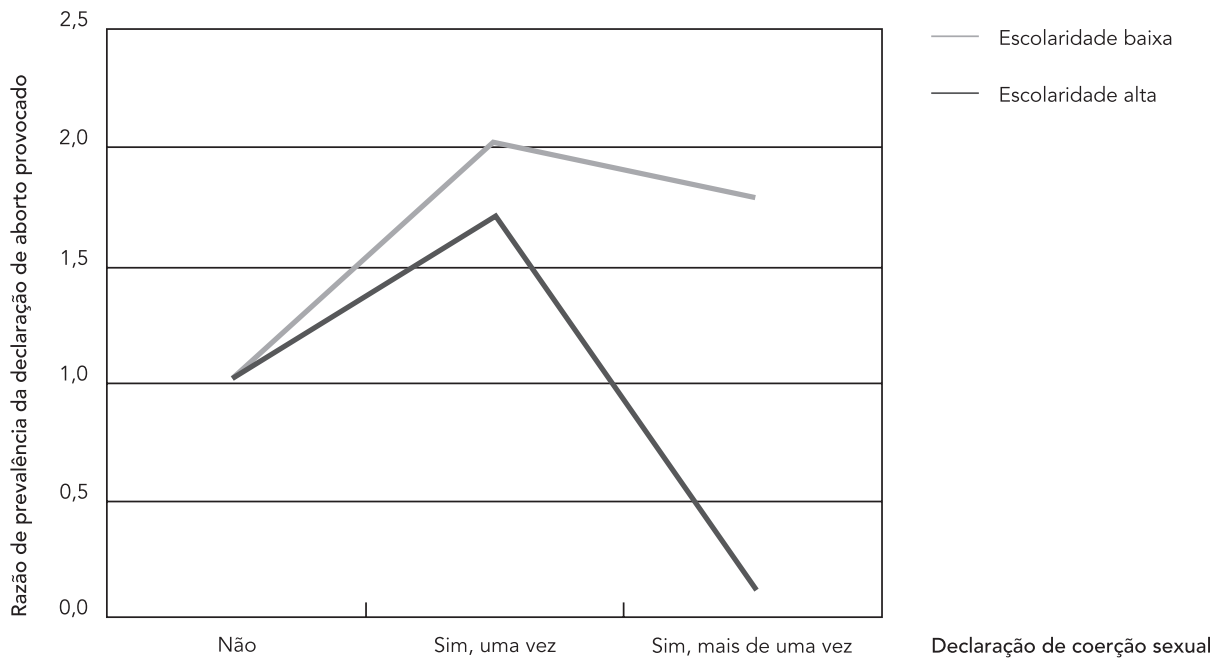

Fonte: Pesquisa GRAVAD, 2002. 
$38,9 \%)$, por apresentarem mais frequentemente trajetória de contracepção/proteção marcada pelo não uso de métodos (54,1\% versus $39,9 \%$ ) e por terem um maior número de parceiros $(36,4 \%$ tiveram mais de 5 parceiros, mesma situação de $13,2 \%$ das que não relataram aborto) e de gestações (média de 1,89 versus 1,5 ).

A Tabela 2 descreve aspectos relacionados à coerção sexual, analisada sob a ótica das mulheres que declaram ou não aborto. As jovens com relato de coerção sexual e que declararam ter abortado apresentavam maior percentual de mães cuja escolaridade era alta $(29,2 \%)$, quando comparadas às jovens que afirmaram não ter realizado aborto (21,8\%). Nota-se que para $29,1 \%$ das jovens que relatam aborto, a relação sexual chegou a acontecer de fato, ao passo que o mesmo ocorreu para $22,2 \%$ das jovens que não mencionaram ter abortado. Entre as entrevistadas sem histórico de abortamento, 31,7\% declararam que a coerção foi forçada pela violência física ou ameaça de violência, mesma situação de 43,3\% das jovens com histórico de abortamento. Tais questões referentes às características de vítimas e perpetradores, às principais estratégias de coerção e aos cenários que favoreceram a ocorrência da violência sexual, utilizando os dados do estudo GRAVAD, já foram abordadas por Moraes et al. 9. Portanto, neste trabalho, nos limitamos a apresentá-las, mas não as discutiremos em maior profundidade.

Em grande parcela das situações de coerção, o agressor era conhecido da vítima, sendo ele o parceiro ou ex-parceiro íntimo. Embora seja pequena a parcela de jovens que relatou coerção praticada por desconhecidos, foi bastante superior nas jovens que relataram aborto $(13,9 \%)$ em comparação com as que não relataram $(1,2 \%)$.

Sobre a revelação de violência, a maior parte das jovens que sofreu coerção relatou ter contado para alguém $(58,1 \%$ sem abortamento e $73,1 \%$ das com abortamento). Amigos e colegas (48,1\% entre as que não abortaram e $56,2 \%$ entre as que abortaram) foram apontados como os mais frequentes confidentes, sendo menor a parcela que relatou aos pais $(19,9 \%$ e $37,7 \%$, respectivamente) e muito diminuta a que relatou essa informação a instituições escolares, policiais e de saúde (3,9\% versus $10,3 \%)$ (Tabela 2$)$.

A Tabela 3 mostra as variáveis significativas na análise univariável e multivariável associadas ao relato de aborto. As variáveis cor de pele, religião de criação, participação nas atividades domésticas, diferença de idade para o parceiro da primeira gestação e idade na primeira gravidez não apresentaram significância estatística na análise univariável e, por esse motivo, não foram incluídas nas tabelas. No modelo multivariável, encontraram-se associadas à prática do aborto, ter residência no Rio de Janeiro e em Salvador, ter escolaridade mais alta (ensino médio/superior/pós-graduação), não ter obtido as primeiras informações sobre relações sexuais com os pais, ter tido maior número de parceiros sexuais, bem como de gestações, e a declaração de ter sofrido coerção sexual uma vez na vida.

$\mathrm{Na}$ análise da associação entre o relato de coerção sexual e o de aborto nos diferentes segmentos sociais, utilizando-se como proxi a variável escolaridade da mãe, em situações em que a coerção ocorreu uma vez, a razão de prevalência de aborto foi de 2,01 (IC95\%: 1,14-3,57) para aquelas cuja mãe tinha escolaridade baixa e de 1,70 (IC95\%: 0,94-3,09) para aquelas cuja mãe tinha escolaridade elevada. Já quando a coerção se apresentou de forma sistemática no cotidiano das jovens, tendo ocorrido mais de uma vez, a razão de prevalência para o aborto foi de 1,79 (IC95\%: 0,99-3,21) para as jovens cuja escolaridade materna era baixa e de 0,11 (IC95\%: 0,01-0,94) para aquelas cujas mães tinham escolaridade elevada (Figura 1).

\section{Discussão}

O planejamento da gravidez permite às mulheres um maior controle de sua trajetória de vida, bem como dos aspectos relacionados à gestação ${ }^{2}$. No Brasil, persiste um cenário no qual existem substanciais dificuldades para a regulação da fertilidade, no qual o aborto é ilegal, o acesso à contracepção e aos serviços de saúde é insuficiente e persistem as iniquidades de gênero 1 . Ainda assim, quando uma jovem se depara com uma gravidez não prevista, o aborto aparece como alternativa para a resolução do problema.

Neste trabalho, em conformidade com outros estudos que utilizaram os dados do GRAVAD, encontramos associação entre maior prevalência de aborto e maior escolaridade das jovens 5 , maior número de parceiros e de gestações. Entre as jovens que residiam em Porto Alegre 14 e as que obtiveram as primeiras informações sobre relações sexuais com os pais, a prevalência de aborto foi menor. Destaca-se ainda a associação da prática do aborto à declaração de ter sofrido coerção sexual uma vez na vida. Esses dados sinalizam para os determinantes sociais e econômicos do aborto e evidenciam não ser essa uma prática que pode ser compreendida apenas da perspectiva individual.

Os determinantes socioculturais se apresentam, no caso do aborto, de maneira não apenas explícita, mas também complexa. A informação sobre contracepção, que, em uma perspectiva 
individual, é tida como a principal estratégia preventiva, parece não operar dessa forma no caso do aborto. A associação encontrada entre a prática de aborto e a elevada escolaridade da jovem indica que outros valores se interpõem entre a informação e o comportamento. As trajetórias escolares e profissionais são privilegiadas e a gravidez é percebida com um evento que pode interromper ou retardar semelhantes projetos, como indicam Menezes et al. 5. Em tal contexto, as jovens mais privilegiadas economicamente, além de ter maior acesso à contracepção, podem optar por um aborto mais seguro, mesmo que de forma ilegal. Além disso, Bajos \& Marquet 15 chamam a atenção para o fato de que, em sociedades como a nossa, em que a desigualdade de gênero ainda é bastante presente, um maior nível educacional "empodera" as mulheres, fazendo com que elas conquistem maior autonomia relacional e sexual, o que se reflete também na escolha por ter ou não filhos e por continuar ou não uma gravidez.

Por outro lado, os dados sugerem que a informação faz mais sentido e, portanto, incide sobre o comportamento quando inserida em um contexto de proximidade e de relações mais igualitárias. Logo, jovens que obtiveram as primeiras informações sobre relações sexuais com os pais, e que possivelmente têm uma relação mais próxima com eles, encontram-se menos vulneráveis à prática do aborto. Esse dado também é evidenciado nos achados de Peres \& Heilborn ${ }^{1}$, nos quais a mãe é considerada importante interlocutora dos filhos, tendo papel essencial na decisão da manutenção ou da finalização de uma possível gravidez.

O maior número de parceiros sexuais relatado pelas jovens que abortaram pode sugerir um estilo de relacionamentos afetivo-sexuais diferente das jovens que não abortaram. Esse tipo de comportamento pode estar associado indiretamente ao risco de que ocorra uma gravidez não prevista, que seja findada em aborto, ou pode ainda atestar uma ruptura com os valores tradicionais de gênero e de reprodução, colocando o exercício da sexualidade como uma prerrogativa também feminina, bem como o controle - mesmo que via aborto - da reprodução.

Entretanto, a associação entre o aborto e os determinantes socioculturais torna-se mais evidente na relação encontrada dessa prática com a declaração de ter sofrido coerção sexual uma vez na vida. Neste estudo, a prevalência de coerção sexual entre mulheres jovens que tiveram ao menos uma gravidez $(22,8 \%)$ é semelhante à encontrada por Schraiber et al. 16, estudando usuárias de atenção primária na rede pública de São Paulo (24,2\%), sendo superior à encontrada por Moraes et al. ${ }^{9}(16,5 \%)$, analisando dados do inquérito GRAVAD, nos quais estavam inclusas também jovens que relataram não ter tido nenhuma gravidez.

A associação entre a declaração de coerção sexual e de aborto se manteve mesmo após a incorporação das variáveis incluídas no modelo final (cidade, escolaridade da jovem, número de parceiros e número de gravidezes). Esse dado evidencia o quadro de vulnerabilidade de gênero em que as jovens estão inseridas, no qual a declaração de coerção sexual aparece associada a outros fatores, como o recurso ao aborto, denotando certa precariedade nas negociações em termos de sexualidade e reprodução. A falta de controle das condições em que têm relações sexuais, por parte das mulheres, aliada ao modelo cultural de dominação masculina, contribui para altas taxas de gravidez não prevista e, consequentemente, de abortos, dado também demonstrado por Faúndes \& Barzelatto 17. O aborto aparece assim como um elemento que se conjuga com a coerção sexual, apresentandose, sobretudo, nas situações em que a coerção é um evento esporádico (uma vez), talvez como uma estratégia do controle sobre a reprodução. Como sugerem Fisher et al. 18, o histórico de coerção sexual pode resultar em mudanças psicológicas que interferem negativamente no desejo da mulher de levar a gestação a termo. Além disso, é interessante traçar um paralelo entre este achado e o trabalho de Ayres 12, que mostra a associação entre a vulnerabilidade à AIDS e a violência. Este autor enfatiza que a diminuição da autoestima das jovens expostas à violência pode levá-las a ter menos chances de adotar atitudes de proteção.

Cordeiro et al. 8 salientam a importância da compreensão do que é entendido como constrangimento e do que é aceitável ou não como prática sexual dentro dos cenários culturais estudados, para facilitar uma abordagem direta das situações relacionais. No estudo GRAVAD foi abordada uma definição mais ampla de violência sexual, pelo conceito de coerção, que inclui casos nos quais a violência não se concretizou e que, mesmo assim, como demonstrado no presente artigo, possuem impacto nas trajetórias reprodutivas das jovens.

Os diferentes significados e impactos da coerção sexual nas biografias das jovens podem ser vislumbrados quando consideramos as diferenças evidenciadas entre as jovens que relataram experienciar uma e mais de uma situação de coerção sexual. Como os dados sugerem, quando a coerção é percebida como um evento isolado, perpetrada por um desconhecido, há maior tendência de recurso ao aborto por parte das jovens 
como estratégia de controle sobre a reprodução. Já quando a coerção aparece inserida de forma mais sistemática no cotidiano, mediante relato de mais de uma situação e tendo como agressor, na maioria das vezes, uma pessoa próxima, como é demonstrado pela literatura 16,19, nota-se que a declaração da ocorrência de aborto é menos frequente, em especial entre as jovens cujas mães têm maior escolaridade. Portanto, se a associação entre aborto e coerção sexual evidencia o quadro de vulnerabilidade individual e social em que as jovens estão inseridas, a repetição das experiências de coerção ao longo da trajetória, particularmente entre as jovens pertencentes aos segmentos sociais mais privilegiados, sinaliza um agravamento dessa vulnerabilidade. O efeito "protetor" (RP = 0,11; IC95\%: 0,01-0,94) que a coerção sexual apresenta para o aborto no segmento estudado, pode sinalizar justamente uma maior dificuldade das jovens em romper com a situação e buscar condições de controle e autonomia em temos do exercício da sexualidade e da reprodução. Há várias razões de ordem econômica, social e cultural que podem estar associadas a esse comportamento, como por exemplo, a dependência econômica para com os pais ou parceiros, a vergonha e o medo, tanto de violência física quanto da condenação social. Isso fica evidente quando dialogamos com os achados de Dantas-Berger \& Giffin 20 , nos quais quando a coerção sexual é praticada pelo parceiro íntimo, ela é entendida como uma "cláusula" prevista nas obrigações conjugais, sendo recorrente, mas não nomeada como violência.

A associação entre a ocorrência de violência sexual e a perda da gestão sobre o planejamento reprodutivo é também evidenciada em outros estudos, como na pesquisa realizada por D'Oliveira et al. 21 que, estudando mulheres de São Paulo e da Zona da Mata Pernambucana, encontraram uma associação entre o relato de violência e o maior número de filhos.

A maioria das jovens, especialmente aquelas que mencionaram ter recorrido ao aborto, relatou a ocorrência de coerção a alguém, destacando-se no papel de interlocutores amigos e colegas, como já evidenciado no trabalho de Moraes et al. ${ }^{9}$. As instituições policiais, de ensino e de saúde foram poucas vezes informadas desse tipo de violência, desconhecendo sua ocorrência e sua magnitude. As mulheres que abortaram, tenderam a revelar em maior proporção a ocorrência de coerção também para os pais, observando-se um aumento das revelações para a figura paterna, e para a instituição policial, em comparação com as que não abortaram. Este aumento na revelação aos pais e à policia pode estar relacionado ao fato de que, para tais jovens, foram mais frequentes as agressões por desconhecidos, quando comparadas às mulheres sem histórico de abortamento.

$\mathrm{O}$ fato de as mulheres reconhecerem a agressão de que foram vítimas de violência, especialmente quando o agressor é o parceiro íntimo, traz consigo todas as implicações psicossociais que permeiam o problema. Além disso, essa dificuldade impede que elas procurem assistência jurídico-policial, representando um obstáculo para a transformação da situação 16 .

No que se refere aos serviços de saúde, alguns estudos 16,22 apontam certa dificuldade das mulheres de fazer a revelação de que sofreram violência sexual. Elas não sabem exatamente como ou não dispõem de linguagem adequada para caracterizar aos profissionais de saúde o que foi vivido. Além disso, a vergonha, o sentimento de culpa, a humilhação e o medo de represálias e de descrédito se tornam uma barreira para iniciar conversas sobre o assunto. Já os profissionais de saúde não se sentem suficientemente habilitados para lidar com esse tipo de queixa, que não se encaixa na caracterização clássica de patologia com a qual eles estão acostumados a trabalhar, e evitam tocar no assunto 16 .

O silenciamento da coerção sexual às instituições públicas contribui, portanto, para aumentar a vulnerabilidade das jovens na medida em que impede, seja pela inexistência de confiança ou de políticas específicas, o acesso a recursos educativos, jurídicos e de saúde que poderiam auxiliar na ruptura das situações de coerção e na prevenção contra novas ocorrências. Esse é justamente o plano da vulnerabilidade denominada programática que, de acordo com Ayres et al. 11, pode reforçar ou diminuir o risco individual. Nesse sentido, a vulnerabilidade é resultante da relação intrínseca entre o comportamento individual e determinantes sociais, entre os quais se incluem a existência e o acesso a instituições e políticas públicas 23.

Por fim, devem ser consideradas as limitações do presente estudo. Apesar de a pesquisa GRAVAD ter sido planejada com a intenção de criar uma relação de confiança entre pesquisador e entrevistado, proporcionando condições mais adequadas para o relato de experiências íntimas, com vistas a aumentar a fidedignidade dos dados 24 , há que se ter em conta a possível ocorrência de subestimação de ambos os fenômenos estudados, por se tratar de temas velados e de difícil acesso a informações 9 .

Os diferentes significados atribuídos à expressão "ter relações sexuais contra a vontade" possivelmente apresentam importantes variações segundo o pertencimento social das entrevistadas. A associação de "contra a vontade" com 
violência depende da construção social que as mulheres possuem sobre o que é violência. O que para algumas mulheres é aceitável e tido como "direito do homem", para outras se configura como uma situação de violência 25 .

Além disso, a comparação da associação entre aborto e coerção sexual entre os diferentes segmentos sociais, apesar de apresentar tendência semelhante tanto na análise univariável quanto na multivariável, deve ser interpretada com cautela em razão do número restrito de entrevistadas que relatou aborto e mais de um episódio de coerção.

\section{Conclusão}

Os resultados do presente estudo sinalizam a necessidade de contextualizar os diferentes eventos de saúde sexual e reprodutiva - como a coerção sexual e o aborto - em um quadro maior de vulnerabilidade social. Os determinantes socioeconômicos, como a classe social e a cidade de residência, que incidem diretamente sobre outros aspectos da trajetória das jovens - como a escolaridade, o número de gestações e parcerias sexuais e as experiências de coerção sexual - indicam que, especialmente no que concerne às jovens mulheres, as modificações no cenário da violência sexual e do recurso ao aborto não se dão exclusivamente no plano individual. Como demonstrado no artigo, ter maior escolaridade ou pertencer aos segmentos sociais mais elevados, que teoricamente possibilitam o maior acesso a informações e recursos de prevenção, podem não proteger as jovens contra situações de coerção sexual e gravidez não prevista. Por outro lado, a perpetuação das situações de coerção sexual, sobretudo quando o agressor é alguém da rede de relações da vítima, configura um contexto com o qual as jovens apresentam maior dificuldade de ruptura da situação, complicando também a assunção do controle da sexualidade e da reprodução.

Por conseguinte, as ações voltadas à prevenção da violência sexual, incluindo a coerção, devem ser incluídas nas estratégias de saúde sexual e reprodutiva dirigidas tanto às mulheres quanto aos homens e, particularmente, à população jovem. O envolvimento da escola, dos serviços de saúde e das instituições judiciais é fundamental para a diminuição da vulnerabilidade programática e a consequente diminuição do risco individual.

Em termos da produção do conhecimento, são imprescindíveis mais estudos que busquem identificar a associação entre as trajetórias afetivo-sexuais e decisões reprodutivas de homens e mulheres com os diferentes tipos de violência. É somente mediante conhecimento detalhado desses contextos de vulnerabilidade que poderemos ter ações mais eficazes a fim de garantir a autonomia e a liberdade no exercício da sexualidade e reprodução dos jovens.

\section{Resumo}

Neste estudo investigou-se a relação entre a prática do aborto e a declaração de coerção sexual. Os dados foram provenientes do GRAVAD, inquérito domiciliar com amostragem probabilística estratificada, realizado com jovens de 18 a 24 anos, no Rio de Janeiro, em Porto Alegre e em Salvador, Brasil. A amostra do presente artigo foi composta por 870 entrevistas de mulheres que reportaram ter tido gravidez. A declaração de aborto mostrou-se associada ao relato de uma experiência de coerção sexual, bem como à maior escolaridade da jovem, a não ter obtido as primeiras informações sobre relações sexuais com os pais e a um maior número de gravidezes e de parceiros. A associação entre o aborto e a coerção sexual evidencia um quadro de vulnerabilidade de gênero e denota a precariedade das negociações em termos de sexualidade e reprodução. $O$ silenciamento da coerção sexual às instituições públicas contribui para aumentar a vulnerabilidade das jovens, impedindo o acesso a recursos educativos, jurídicos e de saúde, que poderiam auxiliar na ruptura das situações de coerção e prevenção de novas ocorrências.

Aborto Induzido; Violência Sexual; Vulnerabilidade 


\section{Colaboradores}

F. B. Pilecco participou da elaboração e execução do artigo, sendo responsável pela revisão bibliográfica, análise estatística e redação do artigo. D. R. Knauth participou da elaboração do estudo, sendo responsável pela aquisição dos dados, pela orientação da revisão bibliográfica, pela revisão do artigo e incorporação de sugestões e por parte da redação final. A. Vigo participou da análise estatística e interpretação dos dados e de toda a confecção e revisão do artigo.

\section{Referências}

1. Peres SO, Heilborn ML. Cogitação e prática do aborto entre jovens em contexto de interdição legal: o avesso da gravidez na adolescência. Cad Saúde Pública 2006; 22:1411-20.

2. Font-Ribera L, Perez G, Salvador J, Borrell C. Socioeconomic inequalities in unintended pregnancy and abortion decision. J Urban Health 2008; 85:125-35.

3. Departamento de Ciência e Tecnologia, Secretaria de Ciência, Tecnologia e Insumos Estratégicos, Ministério da Saúde. 20 anos de pesquisas sobre aborto no Brasil. Brasília: Ministério da Saúde; 2009. (Série B. Textos Básicos de Saúde).

4. The Alan Guttmacher Institute. Sharing responsibility: women, society and abortion worldwide. New York: The Alan Guttmacher Institute; 1999.

\section{Agradecimentos}

O projeto Gravidez na Adolescência: Estudo Multicêntrico sobre Jovens, Sexualidade e Reprodução no Brasil foi originalmente elaborado por Maria Luiza Heilborn (Programa em Gênero, Sexualidade e Saúde, Instituto de Medicina Social, Universidade do Estado do Rio de Janeiro), Michel Bozon (Institut National d'Études Démographiques), Estela M. L. Aquino (Programa de Estudos em Gênero e Saúde, Instituto de Saúde Coletiva, Universidade Federal da Bahia), Daniela Knauth e Ondina Fachel Leal (Núcleo de Pesquisa em Antropologia do Corpo e da Saúde, Universidade Federal do Rio Grande do Sul). Agradecemos a Ceres G. Victora, Fabíola Rohden, Cecilia McCallum, Tania Salem, Elaine Brandão e aos demais membros da equipe GRAVAD, bem como ao consultor estatístico do estudo, Antônio José Ribeiro Dias (Fundação Instituto Brasileiro de Geografia e Estatística). Agradecemos, ainda, o apoio financeiro da Fundação Ford e ao Programa de Bolsas do Conselho Nacional de Desenvolvimento Científico e Tecnológico. À Coordenação de Aperfeiçoamento de Pessoal de Nível Superior (CAPES/SPM; bolsa de mestrado - edital Enfrentamento da Violência contra as Mulheres 003/2008).

5. Menezes GMS, Aquino EML, Silva DO. Induced abortion during youth: social inequalities in the outcome of the first pregnancy. Cad Saúde Pública 2006; 22:1431-46.

6. Menezes GMS. Aborto e juventude: um estudo em três capitais brasileiras [Tese de Doutorado]. Salvador: Instituto de Saúde Coletiva, Universidade Federal da Bahia; 2006.

7. Heise L, Moore K, Toubia N. Sexual coercion and reproductive health: a focus on research. New York: Population Council; 1995.

8. Cordeiro F, Heilborn ML, Cabral CS, Moraes CL. Entre negociação e conflito: gênero e coerção sexual em três capitais brasileiras. Ciênc Saúde Coletiva 2009; 14:1051-62. 
9. Moraes CL, Cabral CS, Heilborn ML. Magnitude e caracterização de situações de coerção sexual vivenciadas por jovens de três grandes capitais brasileiras: Porto Alegre, Rio de Janeiro e Salvador. Cad Saúde Pública 2006; 22:1493-504.

10. Moore AM, Awusabo-Asare K, Madise N, JohnLangba J, Kumi-Kyereme A. Coerced first sex among adolescent girls in Sub-Saharan Africa: prevalence and context. Afr J Reprod Health 2007; 11:62-82.

11. Ayres JRCM, França Júnior I, Calazans GJ, Saletti Filho HC. Vulnerabilidade e prevenção em tempos de AIDS. In: Barbosa RM, Parker RG, editores. Sexualidades pelo avesso: direitos, identidade e poder. São Paulo: Editora 34; 1999. p. 49-72.

12. Ayres JRCM. O jovem que buscamos e o encontro que queremos ser: a vulnerabilidade como eixo de avaliação de ações preventivas do abuso de drogas, DST e AIDS entre crianças e adolescentes. http:// www.crmariocovas.sp.gov.br/pdf/ideias_29_p015024_c.pdf (acessado em 22/Dez/2009).

13. Teixeira AMFB. O uso de métodos de contracepção/proteção entre jovens de 18 a 24 anos de três capitais brasileiras [Tese de Doutorado]. Porto Alegre: Universidade Federal do Rio Grande do Sul; 2006.

14. Aquino EML, Almeida MC, Araújo MJ, Menezes G. Gravidez na adolescência: a heterogeneidade revelada. In: Heilborn ML, Aquino EML, Bozon $\mathrm{M}$, Knauth DR, editores. O aprendizado da sexualidade: reprodução e trajetórias sociais de jovens brasileiros. Rio de Janeiro: Garamond/Editora Fiocruz; 2002. p. 309-60.

15. Bajos N, Marquet J. Research on HIV sexual risk: social relations-based approach in a cross-cultural perspective. Soc Sci Med 2000; 50:1533-46.
16. Schraiber L, d'Oliveira AF, Hanada H, Figueiredo W, Couto M, Kiss L, et al. Violência vivida: a dor que não tem nome. Interface Comum Educ Saúde 2003; 7:41-54.

17. Faúndes A, Barzelatto J. O drama do aborto: em busca de um consenso. Campinas: Editora Komedi; 2004.

18. Fisher WA, Singh SS, Shuper PA, Carey M, Otchet F, MacLean-Brine D, et al. Characteristics of women undergoing repeat induced abortion. CMAJ 2005; 172:637-41.

19. Diniz D. Fórum: violência sexual e saúde. Posfácio. Cad Saúde Pública 2007; 23:477-8.

20. Dantas-Berger SM, Giffin K. A violência nas relações de conjugalidade: invisibilidade e banalização da violência sexual? Cad Saúde Pública 2005; 21:417-25.

21. D'Oliveira AF, Schraiber LB, França Júnior I, Ludermir AB, Portella AP, Diniz CS, et al. Factors associated with intimate partner violence against Brazilian women. Rev Saúde Pública 2009; 43:299-311.

22. Villela WV, Lago T. Conquistas e desafios no atendimento das mulheres que sofreram violência sexual. Cad Saúde Pública 2007; 23:471-5.

23. Muñoz Sánchez AI, Bertolozzi MR. Pode o conceito de vulnerabilidade apoiar a construção do conhecimento em Saúde Coletiva? Ciênc Saúde Coletiva 2007; 12:319-24.

24. Rossier C. Estimating induced abortion rates: a review. Stud Fam Plann 2003; 34:87-102.

25. Faúndes A, Rosas CF, Bedone AJ, Orozco LT. Violência sexual: procedimentos indicados e seus resultados no atendimento de urgência de mulheres vítimas de estupro. Rev Bras Ginecol Obstet 2006; 28:126-35.

Recebido em 22/Mar/2010

Versão final reapresentada em 28/Set/2010 Aprovado em 01/Fev/2011 